\title{
A ORGANIZAÇÃO CURRICULAR DO ENSINO MÉDIO INTEGRADO A PARTIR DO EIXO ESTRUTURANTE: TRABALHO, CIÊNCIA, TECNOLOGIA E CULTURA
}

\section{THE CURRICULUM OF THE HIGH SCHOOL INTEGRATED WITH VOCATIONAL EDUCATION BUILT FROM THE STRUCTURAL AXIS: LABOR, SCIENCE, TECHNOLOGY AND CULTURE}

\author{
Dante Henrique Moura ${ }^{1}$
}

\begin{abstract}
RESUMO
Neste texto discutimos algumas possibilidades de organização curricular do ensino médio integrado a partir de seu eixo estruturante, trabalho, ciência, tecnologia e cultura. Realizamos o estudo a partir de revisão bibliográfica pertinente ao tema. Dividimos o texto em cinco partes: uma aproximação inicial, seguida de uma breve discussão acerca da integração entre trabalho, ciência, tecnologia e cultura. Depois, discorremos sobre as relações entre o projeto político-pedagógico (PPP) e a organização curricular. $\mathrm{Na}$ quarta parte, alcançamos o objetivo central do trabalho que é discutir algumas possibilidades de organização curricular do ensino médio integrado. Finalmente, apresentamos algumas considerações finais, onde destacamos que para se avançar na direção de constituir o ensino médio integrado como política pública educacional é fundamental, dentre outros aspectos, a instituição de quadro próprio de professores, com a realização de novos concursos; a consolidação de planos de carreira em que seja prevista a dedicação exclusiva dos professores e a melhoria salarial; e a melhoria da estrutura física, material e tecnológica das escolas, especialmente nas redes estaduais.
\end{abstract}

Palavras-chave: Ensino Médio integrado - Organização curricular - Educação profissional.

\begin{abstract}
In this paper we discuss some possibilities of high school curriculum integrated with vocational education from its structural axis, labor, science, technology and culture. We conducted the study based on literature review concerning the matter. We divide the text into five parts: an initial approach, followed by a brief discussion about the integration of labor, science, technology and culture. Then, we talk about relations between the political-pedagogical project (PPP) and the curriculum. In the fourth part, we achieved the main objective of the paper is to discuss some possibilities of high school curriculum integrated with vocational education. Finally, we present some concluding remarks, where we emphasize that to move toward high school be built as a public policy education is essential, among other things, the establishment of its own staff of teachers with the implementation of new procurement, the consolidation of career paths as to provide for the dedication of teachers and better salaries, and improving the physical structure, material and technological schools, especially in state schools.
\end{abstract}


Keywords: High-school integrated - Curriculum with vocational education Vocational education.

\section{INTRODUÇÃO}

Neste texto discutimos a organização curricular do ensino médio integrado a partir da integração entre trabalho, ciência, tecnologia e cultura. Realizamos o estudo a partir de revisão bibliográfica pertinente ao tema e de nossos conhecimentos e experiência profissional nessa esfera educacional.

Esclarecemos que o texto não tem caráter exaustivo. O que almejamos é contribuir para o debate político e teórico-metodológico acerca das possibilidades de construção do ensino médio integrado aos cursos técnicos de nível médio como política pública educacional do Estado brasileiro.

Antes de iniciar a discussão acerca do nosso objeto de estudo, convém esclarecer que não vamos enfocar diretamente algumas questões relativas ao ensino médio integrado no atual quadro educacional brasileiro, tais como: a sua pertinência e necessidade de ampliação da oferta; a sua contribuição para o rompimento da dualidade estrutural entre cultura geral e cultura técnica; e a sua aproximação conceitual com a politecnia ou educação tecnológica, uma vez que estamos de acordo com parte significativa da produção já existente acerca dessas questões, as quais fundamentam o presente estudo ${ }^{2}$.

Para melhor localizar o leitor no texto, o dividimos em mais quatro partes além desta aproximação inicial ao tema: na primeira fazemos uma breve discussão acerca da integração entre trabalho, ciência, tecnologia e cultura. Em seguida, discorremos sobre as relações entre o projeto político-pedagógico (PPP) e a organização curricular. Na terceira parte, alcançamos o objetivo central do trabalho que é discutir algumas possibilidades de organização curricular do ensino médio integrado. Finalmente, apresentamos algumas considerações finais sobre os temas em questão. 


\section{TRABALHO, CIÊNCIA, TECNOLOGIA E CULTURA COMO EIXO ESTRUTURANTE DO ENSINO MÉDIO INTEGRADO: UMA BREVE DISCUSSÃO ${ }^{3}$}

Previamente a qualquer proposição acerca da organização curricular do ensino médio integrado é imprescindível buscar compreender como trabalho e tecnologia, articulam-se à ciência e à cultura. É a partir dessa articulação que buscaremos identificar possibilidades metodológicas que contribuam para promover a pretendida integração.

Nesse sentido, compreendemos o trabalho como mediação primeira entre o homem e a natureza e, portanto, elemento central na produção da existência humana ${ }^{4}$. Dessa forma, é na busca da produção da própria existência que o homem gera conhecimentos, os quais são histórica, social e culturalmente acumulados, ampliados e transformados. Nessa perspectiva, o conhecimento é uma produção do pensamento em que se percebem e se representam as relações constitutivas e estruturantes da realidade, enquanto a teoria surge quando essas relações, elevadas ao plano do pensamento, são ordenadas e retiradas do contexto em que foram produzidas e apreendidas originalmente, com o objetivo de potencializar o avanço das forças produtivas. A ciência, nessa linha de raciocínio, é um tipo de conhecimento rigorosamente sistematizado e intencionalmente expresso como conceitos que representam as relações determinadas e apreendidas da realidade considerada. A ciência converte-se, pois, em força produtiva (RAMOS, ? ${ }^{5}$ ).

A história da tecnologia, à luz da concepção de ciência como força produtiva, ocorre no marco da revolução industrial, da qual decorrem em um primeiro momento o taylorismo e o fordismo e, posteriormente, a automação industrial e o toyotismo. Dessa compreensão, surge uma relação entre ciência e tecnologia que se desenvolve na produção industrial. Outra relação decorre do fato que tal desenvolvimento visa satisfazer as necessidades que seres humanos criam para si individual e coletivamente, constituindo-se (as tecnologias) como possibilidades de extensão das capacidades de homens e mulheres. Nesse sentido, a tecnologia é "mediação entre ciência (apreensão e desvelamento do real) e produção (intervenção no real)." (RAMOS, 2004; $2005^{6}$ apud BRASIL, 2007, p. 44) 
Além disso, é necessário compreender a tecnologia como construção social complexa integrada às relações sociais de produção. Portanto, mais que força material da produção, a tecnologia, cada vez mais indissociável das práticas cotidianas, em seus vários campos/diversidades/tempos e espaços, assume uma dimensão sociocultural, uma centralidade geral e não específica na sociabilidade humana. A tecnologia passou a ter um lugar de centralidade em quase todas as práticas sociais, em particular, no processo educativo e de pesquisa. Assim, o trabalho como categoria central de produção de saber, e, trabalho, ciência e tecnologia são indissociáveis (LIMA FILHO, 2005; MOURA, 2007).

Todo esse processo relacional de apreensão, desvelamento e intervenção no real, originado do trabalho enquanto mediação fundamental entre o homem e a natureza, resulta na produção de conhecimentos, teorias, ciência e tecnologia. Cabe-nos incorporar a nossas reflexões 0 fato de que esses movimentos ocorrem a partir das práticas realizadas pelos grupos sociais e, portanto, influenciam e são fortemente influenciados pela cultura desses mesmos grupos. Nesse sentido, compreendemos a cultura como código de comportamento dos indivíduos e grupos que integram determinada sociedade e como manifestação de sua forma de organização política e econômica, no que diz respeito às ideologias que lhe dão sustentação (GRAMSCI, $1991^{7}$ apud BRASIL, 2007, p. 44). Então, por essa forma de pensar, a cultura constitui o modo de vida de um determinado grupo populacional, pois é por meio dela que se produzem símbolos, representações e significados que determinam suas práticas sociais e vice-versa.

Diante disso, a formação integrada, precisa ir além de proporcionar o acesso aos conhecimentos científicos e tecnológicos produzidos e acumulados pela humanidade. Precisa promover o pensamento crítico-reflexivo sobre os códigos de cultura manifestados pelos grupos sociais ao longo da história, como forma de compreender as concepções, problemas, crises e potenciais de uma sociedade e, a partir daí, contribuir para a construção de novos padrões de produção de conhecimento, de ciência e de tecnologia, voltados para os interesses sociais e coletivos.

É a partir desses referenciais que, na próxima seção, vamos discutir as relações entre o projeto político-pedagógico e a organização curricular. 


\section{O PROJETO POLÍTICO-PEDAGÓGICO E A ORGANIZAÇÃO CURRICULAR: BUSCANDO NEXOS}

Nesta parte do texto vamos tratar de algumas questões, a nosso ver, estreitamente vinculadas à organização curricular do ensino médio integrado. Assim, optamos por, inicialmente, localizar a discussão em meio a outras dimensões relacionadas com a construção dessa oferta educacional como política pública do Estado brasileiro, as quais precisam ser consideradas de forma relacional: pressupostos, concepções e princípios; projeto político-pedagógico (PPP); cooperação entre as distintas esferas de governo; financiamento; quadro docente específico e formação inicial e continuada dos profissionais envolvidos; e infra-estrutura física. Todas essas dimensões relacionam-se entre si e repercutem sobre a organização curricular do ensino médio integrado nos sistemas de ensino (da União, dos estados e dos municípios) e em cada escola na qual foi ou será implementado.

Dessa forma, não nos parece razoável falar de uma organização curricular do ensino médio integrado, mas de possibilidades, as quais poderão ser materializadas em função de como se estabelecerão as relações entre as dimensões acima mencionadas em cada caso concreto. Dentre as dimensões acima evidenciadas, vamos tratar neste texto, principalmente, das relações entre a organização curricular e o PPP.

Em primeiro lugar, cabe-nos ressaltar que o ensino médio integrado, em geral, nos sistemas estaduais vem sendo implantado em escolas já existentes e que, portanto, têm uma determinada função social vigente, a qual será alterada pela chegada dessa nova oferta educacional.

Por que muda a função social de uma escola que implanta o ensino médio integrado? Porque muda o tipo de formação anteriormente proporcionada pela instituição. De uma forma geral, há dois perfis de escolas que estão passando ou passarão a incorporar a oferta do ensino médio integrado à suas funções: escolas que trabalham/vam com o ensino médio propedêutico; e escolas que trabalham/vam apenas com os cursos técnicos (concomitantes ou subseqüentes).

Evidentemente, ambas mudam sua função perante a sociedade. Por 
um lado, enquanto o primeiro tipo de escola tinha sua ação educativa centrada na educação de caráter propedêutico e, em conseqüência, dissociada das discussões relativas ao mundo do trabalho e à profissionalização e, em conseqüência, do trabalho e da tecnologia, o outro tipo centrava seus esforços exclusivamente na formação profissional e nas necessidades do sistema de produção, olvidando os conteúdos de cunho mais científicos, culturais e das ciências humanas, próprios do ensino médio. Portanto, afastados de uma formação de caráter mais geral e humanizador.

Além disso, essas escolas necessitam interagir de forma mais intensa com as comunidades nas quais estão inseridas e com a sociedade em geral porque os PPP e os correspondentes planos dos cursos integrados precisam levar em consideração as características e necessidades sociais, econômicas e culturais da população a ser atendida.

Essa mudança de função ante a sociedade exige que o respectivo sistema de ensino e cada comunidade escolar reflitam, discutam e estabeleçam novos consensos mínimos acerca de uma concepção de sociedade, de ciência, de tecnologia, de trabalho, de cultura, de ser humano e, em conseqüência, do ser humano que se deseja formar e, também, sobre como ocorrerá essa formação (MOURA; BARACHO, 2006).

Enfim, a implantação do ensino médio integrado, tendo como eixo estruturante o trabalho, a ciência, a tecnologia e a cultura pode implicar na necessidade de adequar o Plano de Educação no âmbito do respectivo sistema de ensino e, seguramente, exigirá a alteração do PPP das unidades escolares em que os cursos forem implantados. As mudanças do PPP estabelecerão os rumos da organização curricular que vai materializar a proposta da nova oferta educacional, uma vez que essa é parte daquele.

Essa relação estreita entre a organização curricular e o PPP resulta na necessidade de explicitar alguns elementos fundamentais da (re)construção do último, na perspectiva da gestão democrática, como forma de estabelecer nexos entre eles.

Assim, (re)construitr o PPP significa pensar o futuro da escola, planejar o que se quer realizar, com base no que já existe, buscando o possível. É antever um futuro diferente do presente (VEIGA, 2006). 
Em Moura e Baracho (2006), evidenciamos três pressupostos que podem orientar a dinâmica do processo de elaboração do PPP. A construção coletiva como princípio básico de trabalho é o primeiro. Sua assunção permite que o processo conte com o envolvimento de todos os segmentos institucionais, além dos pais e representações da comunidade em que está inserida a escola. Mais que a participação, o real envolvimento dos agentes institucionais nesse processo é fundamental, pois o PPP "dará indicações necessárias à organização do trabalho pedagógico, que inclui o trabalho do professor na dinâmica interna da sala de aula" (VEIGA; 2006, p.14).

Assim, o envolvimento da categoria docente nesse processo representa uma possibilidade de êxito do projeto a ser construído, enquanto o seu afastamento é um forte indicador do contrário. Desse modo, a escassa participação dos segmentos institucionais, principalmente dos docentes, é uma das causas que contribui para que muitos PPP não passem de documentos que apenas atendem às exigências burocráticas dos sistemas de ensino e terminam sendo arquivados e esquecidos. Ou dito de outra forma, esses PPP não têm sentido para o processo pedagógico institucional, pois não conseguem afetar a vida da escola. Não raras vezes, tais documentos são elaborados por pequenos grupos de especialistas contratados exclusivamente para esse fim.

Outro pressuposto é o diálogo com os projetos anteriores e com o vigente, pois embora a árdua tarefa de (re)construir o PPP implique em enfrentar o desafio da mudança e da transformação, tanto na forma como a escola organiza o seu processo pedagógico como na gestão desse, tal movimento não pode ser feito sem considerar as experiências e os conhecimentos produzidos anteriormente. Ao contrário, é imprescindível resgatar as experiências significativas construídas ao longo da história. Não considerá-las, seria, portanto, uma negação à própria história, à cultura e ao conhecimento já produzido pela escola.

Dessa forma, entendemos que a apropriação de outras experiências curriculares é um facilitador para construir e fazer emergir outro PPP que ajude a promover um novo significado de cada escola e que possa contribuir na formação do trabalhador, intelectualmente autônomo, participativo, solidário, crítico e que exija uma (re)inserção digna na sociedade em geral e também no mundo do trabalho. 
O terceiro pressuposto básico e fundamental é vincular, em cada escola, o processo de (re)construção do PPP à formação continuada da equipe dirigente, dos docentes e do pessoal técnico-administrativo por meio de diferentes estratégias que levem o coletivo institucional a desenvolver estudos que permitam refletir sobre a função social da escola a partir de uma determinada concepção de sociedade, de trabalho, de ciência, de tecnologia, de ser humano e, principalmente, do ser humano que a escola se proporá a formar na vigência do novo projeto.

Para mais além da dinâmica de elaboração do PPP cabe-nos discutir acerca de outros elementos que integram o seu conteúdo, as suas bases. Nesse sentido, recorremos a Veiga (2006), para quem a igualdade de condições para acesso e permanência na escola é um princípio a ser perseguido, embora que, para isso, às vezes seja necessário, tratar de forma desigual no ponto de partida para alcançar a igualdade no ponto de chegada (SAVIANI, 1982 apud VEIGA, 2006, p.16). Entretanto, não se pode perder de vista que o objetivo mais estratégico e, portanto, de médio ou longo prazo é alcançar a desejada igualdade de oportunidades desde a entrada. Para tanto é fundamental trabalhar na perspectiva da ampliação quantitativa das vagas com garantia de qualidade para todos.

Adotar como meta a qualidade da educação para todos implica democratizar a escola, de maneira que para isso, é essencial assumir o princípio constitucional da gestão democrática em suas dimensões pedagógica, administrativa e financeira. Na verdade, muito se tem falado e escrito acerca da gestão democrática, mas falta muito a realizar nessa esfera. Em muitas regiões do país, a escolha dos dirigentes escolares está atrelada à vinculação dos postulantes a um alinhamento político-partidário com o grupo que detém o poder estadual ou municipal em cada momento histórico. Em outros casos, quando se supera a barreira da indicação pela via mencionada, a concepção de gestão democrática é reducionista e se resume, muitas vezes, à eleição para o cargo do máximo dirigente escolar. É claro que isso pode representar um avanço em relação à simples nomeação, entretanto, é apenas um indicador, longe de ser determinante de uma gestão efetivamente democrática. Para que a gestão escolar avance na perspectiva de se tornar efetivamente democrática, é urgente buscar a superação dos processos decisórios centrados nos indivíduos ou em 
pequenos grupos - mesmo que eleitos - em benefício de processos de construção e decisões coletivas, que devem envolver, além dos dirigentes, os docentes, o pessoal técnico-administrativo, os estudantes, os seus familiares e a própria comunidade onde está inserida cada unidade escolar. Para isso é fundamental fortalecer as estruturas colegiadas como, por exemplo, os conselhos escolares e os conselhos de classe.

Além disso, a gestão democrática implica em uma "ruptura histórica na prática administrativa da escola, com o enfrentamento das questões de exclusão e reprovação e da não-permanência do aluno na sala de aula, o que vem provocando a marginalização das classes populares [...] implica a construção coletiva de um projeto político-pedagógico ligado à educação das classes populares." (VEIGA, 2006, p. 17-18)

Finalmente, importa que o PPP trate da valorização dos profissionais da educação. Não é possível alcançar resultados diferentes dos atuais sem que sejam mudadas as condições de trabalho dos profissionais da educação. O PPP de uma escola que atua ou atuará no ensino médio integrado, ao discutir, a organização dos tempos e espaços do trabalho docente deverá contemplar horários destinados ao planejamento conjunto das atividades e horários para estudos acerca dos planos dos cursos, assim como para o acompanhamento e a avaliação dos mesmos. Tudo isso aponta para a necessidade de que os docentes envolvidos nessa função possam concentrar suas atividades em uma só unidade educacional ao invés de trabalhar em duas ou até três escolas públicas distintas.

Para viabilizar o trabalho em uma só escola é forçoso discutir a questão salarial, pois a dupla ou tripla jornada dos professores está associada à busca da ampliação da renda familiar por meio de vários vínculos contratuais, situação que contribui para precarizar a qualidade do trabalho. Portanto, apesar de não estar no PPP o poder de decisão acerca do salário dos profissionais da educação é necessário que esse seja um instrumento de tensionamento ao se projetar o ensino médio integrado ao patamar de política pública educacional.

Também é imperioso que o PPP discuta e aponte diretrizes no sentido de garantir a formação continuada dos docentes. No caso do ensino médio integrado, a formação continuada é estratégica e indispensável, pois os professores que atuam ou atuarão nessa esfera educacional, em geral não 
tiveram formação específica para este fim. Isto ocorre por várias razões, uma delas é que estamos diante de uma inovação no quadro educacional brasileiro.

Assim, a partir dos anos 1970 a Lei no 5.692/1971, determinou a obrigatoriedade do segundo grau profissionalizante para todos, o que na prática não ocorreu, de forma que essa proposição não se enraizou na cultura educacional do país ${ }^{8}$. Nos anos 1990, as diretrizes apontavam para a separação obrigatória entre educação profissional e ensino médio (Decreto no 2.208/1997). Já no início dos anos 2000, volta a possibilidade de integração entre o ensino médio e a educação profissional técnica de nível médio, por meio do Decreto no $5.154 / 2004^{9}$.

Assim sendo, o ensino médio integrado é uma nova possibilidade e, além disso, ainda não há formação sistemática no ensino superior brasileiro destinada a profissionais que atuam ou atuarão na educação profissional em geral e, especificamente, nos cursos em discussão.

Também precisamos compreender que essa formação continuada é necessária tanto para os profissionais provenientes dos bacharelados como para os licenciados, embora suas necessidades formativas sejam distintas. Enquanto os bacharéis carecem de formação didático-político-pedagógica que Ihes qualifique para o exercício da docência, aos licenciados falta a apropriação das discussões e conhecimentos relativos ao mundo do trabalho e suas relações com os processos educacionais. Além disso, ambos necessitam apropriar-se de metodologias de (re)construção do conhecimento que permitam promover a integração entre trabalho, ciência, tecnologia e cultura nos processos formativos dos estudantes do ensino médio integrado.

A partir dos referenciais construídos até agora sobre as relações entre trabalho, ciência, tecnologia e cultura e dos nexos estabelecidos entre o PPP e a organização curricular apresentaremos, em seguida, algumas possibilidades acerca da organização curricular do ensino médio integrado.

\section{ELEMENTOS PARA REFLETIR ACERCA DE ALGUMAS POSSIBILIDADES DE ORGANIZAÇÃO CURRICULAR DO ENSINO MÉDIO INTEGRADO}

São várias as possibilidades de organização curricular do ensino médio integrado. Assim, é muito importante que cada unidade escolar, a partir de 
diretrizes gerais dos respectivos sistemas de ensino e apoiado na participação coletiva dos sujeitos envolvidos e nas teorias educacionais busque a respectiva solução, pois ninguém mais do que o próprio grupo, o próprio coletivo conhece a sua realidade e, portanto, está mais habilitado para tomar decisões a respeito do currículo que vai levar à prática. A partir dessas considerações, apresentamos, a modo de exemplo, algumas idéias que podem contribuir com essa construção, as quais estão sujeitas a análises, críticas, sugestões, revisões ou substituição por outras possibilidades compatíveis com a realidade de cada escola.

Compreendemos que organizar o currículo de forma integrada implica em romper com falsas polarizações, oposições e fronteiras consolidadas ao longo do tempo. Como ponto de partida é preciso ratificar que o ensino médio integrado exige que a relação entre conhecimentos gerais e específicos seja construída de forma contínua ao longo da formação, sob os eixo do trabalho, da ciência, da tecnologia e da cultura, ao invés de, inicialmente, se concentrar os conteúdos vinculados à educação geral e, posteriormente, proporcionar os componentes curriculares da formação técnica específica.

Adotar esse pensamento implica na necessidade de contribuir para acabar com a dicotomia entre as disciplinas de formação geral e as disciplinas de formação profissional. Isso representa, para os educadores que historicamente trabalham com as disciplinas de formação geral, a possibilidade de avançar na compreensão do sentido da educação que é proporcionada aos estudantes. Esses professores serão instigados a buscar relações entre a ciência com a qual trabalham e o seu sentido enquanto força material produtiva para a sociedade em geral e para o cidadão-trabalhador em cuja formação o docente está participando. É, portanto, uma oportunidade para que esses docentes superem tendências academicistas, livrescas, discursivas e reprodutivas das práticas pedagógicas que permeiam, de forma recorrente, essa esfera educacional. Já para os docentes da formação profissional, criam-se oportunidades de superar a perspectiva, muitas vezes, exageradamente técnico-operacional deste ensino e, ao invés disso, aproximar-se de um enfoque que contribua para a apropriação das condições sociais, históricas e culturais de produção e utilização dos conhecimentos científicos, técnicos e tecnológicos que estão na base de cada curso (MACHADO, 2006). 
O movimento criado por essa nova forma de atuação docente, em ambos os casos, visa contribuir para o enfrentamento da tensão dialética entre pensamento científico e pensamento técnico, na busca de outras relações "entre teoria e prática, visando instaurar outros modos de organização e delimitação dos conhecimentos." (MACHADO, 2006, p. 54).

Após as análises e reflexões desenvolvidas ao longo do documento, passaremos a discutir a organização curricular propriamente dita, ou seja, como os componentes curriculares podem ser organizados de modo a contribuir para a formação humana integral.

Em geral, quando se discute currículo integrado há uma tendência a se questionar, a nosso ver corretamente, o espaço das disciplinas, alegando-se que ao longo da história, a concepção disciplinar do currículo isola em compartimentos estanques e incomunicáveis cada uma das disciplinas que objetivam trazer para o ambiente escolar os conhecimentos de um determinado ramo da ciência, os quais, para chegarem até a escola precisam ser didatizados, transformando-se em conhecimentos escolares. Os conhecimentos escolares se diferenciam dos conhecimentos científicos porque são retirados/isolados da realidade social, cultural, econômica, política etc. em que foram produzidos e transpostos para a situação escolar. Nesse processo, evidentemente, perdem-se muitas das conexões existentes entre o ramo da ciência em questão e as demais ciências. Por isso, é necessário diferenciar conhecimento escolar de conhecimento científico.

Como forma de resolver essa questão ou, pelo menos, minimizar os prejuízos decorrentes da organização disciplinar dos currículos, tem surgido, ao longo da história, propostas que organizam o currículo a partir de outras estratégias. É muito rica a variedade de denominações. Mencionaremos algumas dessas metodologias, apenas a título de exemplo. São propostas que tratam da aprendizagem baseada em: problemas; centros de interesses; projetos; complexos temáticos; investigação do meio, entre outras.

Essas metodologias buscam romper com a centralidade das disciplinas nos currículos e substituí-las por aspectos mais globalizadores e que abranjam a complexidade das relações existentes entre os ramos da ciência no mundo real.

Entretanto, apesar de potenciais vantagens que trazem essas metodologias ao aproximarem mais os conhecimentos escolares dos científicos, 
também existem riscos e fragilidades. Em primeiro lugar, é preciso destacar que, a grande maioria dos relatos de experiências nessa esfera, se restringem às séries iniciais de escolarização, nas quais não se exige grande aprofundamento dos conceitos no interior das disciplinas escolares.

No caso do ensino médio, essas metodologias encontram barreiras em função da necessidade do aprofundamento dos conceitos inerentes às disciplinas escolares, já que cada uma se caracteriza por ter objeto próprio de estudo e método específico de abordagem. Dessa maneira, tem se revelado praticamente impossível desenvolver propostas globalizadoras que abranjam os conceitos e especificidades de todas as disciplinas curriculares.

Assim, as propostas voltadas para o ensino médio, em geral, estão baseadas em metodologias mistas (SANTOMÉ, 1998), as quais são desenvolvidas em, pelo menos, dois espaços e tempos. Um voltado para as denominadas atividades integradoras e outro destinado ao aprofundamento conceitual no interior das disciplinas. É a partir daí que vamos apresentar uma possibilidade de organização curricular do ensino médio integrado.

Dessa forma, propomos uma organização por disciplinas (recorte do real para aprofundar conceitos) com atividades integradoras (imersão no ou simulação do real para compreender a relação parte totalidade por meio de atividades interdisciplinares).

Há dois pontos cruciais nessa proposta: a definição das disciplinas com a respectiva seleção de conteúdos; e a definição das atividades integradoras, pois é necessário que ambas sejam efetivadas a partir das interrelações existentes entre os eixo constituinte do ensino médio integrado, ou seja, o trabalho, a ciência, a tecnologia e a cultura.

No que concerne à seleção dos conteúdos disciplinares importa também observar as possibilidades de superposição e a necessidade de evitá-las. Essa não é tarefa simples, tendo em vista a separação histórica à qual já nos referimos anteriormente entre conteúdos da formação geral e conteúdos da formação profissional. Além disso, tal separação é potencializada pelas distintas formações dos professores que historicamente atuam em cada um desses espaços educacionais.

Assim, para minimizar tais superposições sem fazer reduções do currículo, ratificamos a necessidade de proporcionar a formação continuada dos 
docentes no sentido de que se apropriem da concepção e dos princípios do ensino médio integrado. Igualmente importante é organizar os tempos e os espaços de atuação dos professores visando garantir o planejamento e o acompanhamento conjunto das atividades curriculares.

Com relação às atividades integradoras, optamos por não especificar denominações, embora haja várias na literatura, cada uma com suas especificidades. Assumimos essa postura por compreendemos que tal definição é função de cada coletivo, a partir da realidade concreta vivenciada, o que inclui as peculiaridades e possibilidades da rede de ensino e da unidade escolar, assim como as características sociais, econômicas, políticas, culturais e laborais da sociedade, do entorno escolar e dos sujeitos estudantes e professores.

Entretanto, de forma coerente com o eixo que sustenta a concepção de ensino médio integrado aqui discutida, é importante que as atividades integradoras sejam concebidas a partir do trabalho como primeira mediação entre o homem e a natureza e de suas relações com a sociedade, com a ciência, com a tecnologia e com a cultura.

Desse modo, sugerimos que as atividades integradoras (aulas de campo, elaboração de projetos, construção de protótipos, iniciação científica etc.) sejam desenvolvidas a partir de várias estratégias/temáticas que incluam a problemática do trabalho de forma relacional da seguinte forma: Trabalho/Natureza; Trabalho/Sociedade; Trabalho/Ciência e Tecnologia; Trabalho/Cultura.

Assim sendo, a cada período letivo a(s) atividade(s) integradora(s) poderá(rão) ser planejada(s) a partir das relações entre situações reais existentes nas práticas sociais concretas (ou simulações) e os conteúdos das disciplinas, tendo como fio condutor as conexões entre o trabalho e as demais dimensões acima evidenciadas.

Essa forma de organizar o currículo, a nosso ver, contribui não apenas para incorporar o trabalho como princípio educativo ao processo formativo, como também fortalecer os demais elementos que constituem o eixo estruturante do ensino médio integrado sem correr o risco de realizar abordagens demasiadamente gerais e, portanto, superficiais, uma vez que as disciplinas, se bem planejadas, cumprirão o papel do necessário aprofundamento. 


\section{CONSIDERAÇÕES FINAIS}

Reservamos para esta parte final do texto uma breve discussão, quase a modo de revisão, acerca de algumas condições básicas necessárias à materialização do ensino médio integrado como política pública de Estado.

Para torná-la realidade é preciso que os gestores nacionais, estaduais e municipais implementem medidas concretas que possam gerar a confiança por parte dos educadores no sentido de que realmente se está construindo uma política educacional pública de âmbito nacional. Dessa maneira, além da geração de condições de tempo e de espaço adequados ao trabalho docente e de estratégias de formação continuada, outras medidas precisam ser perseguidas (BRASIL, 2007):

- a instituição de quadro próprio de professores, com a realização de novos concursos;

- a consolidação de planos de carreira em que seja prevista a dedicação exclusiva dos professores e a melhoria salarial; e

- a melhoria da estrutura física, material e tecnológica das escolas.

Apesar de essas condições serem extremamente necessárias, sabemos que não estão dadas. É por isso que os sistemas de ensino e as instituições escolares não podem apenas esperar que elas sejam plenamente atingidas para só então se construir um projeto político-pedagógico em que se acordem os princípios e as bases do ensino médio integrado à educação profissional. Por vezes, é o seu desenvolvimento que fundará as bases para a conquista das condições.

Assim, como esses movimentos não são lineares, não podemos esperar pela consolidação da nova perspectiva apresentada para, somente a partir dela, materializar as novas concepções, cabe-nos construir esse novo caminho nas brechas que cavamos no tecido social, político e econômico vigente. 


\section{REFERÊNCIAS}

BARACHO, Maria das Graças; MOURA, Dante Henrique; PEREIRA, Ulisséia Ávila; SILVA, Antônia Francimar. Algumas reflexões e proposições acerca do ensino médio integrado à educação profissional técnica de nível médio. IN: SILVA, Antônia Francimar; FERNANDES, Carmem Monteiro; MOURA, Dante Henrique e outros (8). Ensino médio integrado à educação profissional: integrar para que? Brasília: MEC, 2006, p.17-39.

BRASIL. MINISTÉRIO DA EDUCAÇÃO. Educação Profissional Técnica de Nível Médio Integrada ao Ensino Médio. Documento Base. Brasília, 2007. Disponível em: <http://portal.mec.gov.br/setec/arquivos/pdf/documento_base.pdf>. Acesso em: 20.12.2007.

FRIGOTTO, Gaudêncio; CIAVATTA, Maria (Orgs.) A formação do cidadão produtivo. A cultura do mercado no ensino médio técnico. Brasília: INEP/MEC, 2006.

FRIGOTTO, Gaudêncio; CIAVATTA, Maria; e RAMOS, Marise Nogueira (Orgs.) Ensino médio integrado: concepção e contradições. São Paulo: Editora Cortez, 2005, 175p.

KUENZER, Acácia Zeneida. Ensino médio e profissional: as políticas do Estado neoliberal. São Paulo: Cortez, 1997, 104p.

LIMA FILHO, Domingos Leite. A universidade tecnológica e sua relação com o ensino médio e a educação superior: discutindo a identidade e o futuro dos CEFETs. Perspectiva - Revista do Centro de Ciências da Educação da UFSC, Florianópolis, v. 23, n. 2, p. 349-380, 2005. 
LIMA FILHO, Domingos Leite; GARCIA, Nilson Marcos Dias. Politecnia ou educação tecnológica: desafios ao Ensino Médio e à educação profissional. Anais da 27ª Reunião Anual da ANPEd. ANPEd: Caxambu, 2004.

MACHADO, Lucília Regina de Souza. Ensino Médio e Técnico com Currículos Integrados: propostas de ação didática para uma relação não fantasiosa. In: TVescola. Programa Salto para o futuro. Ensino médio integrado à educação profissional. Boletim 07, maio/junho de 2006, p. 51-68. Setembro de 2006. Disponível em <http://www.tvebrasil.com.br/salto/> Acesso 22.09.2007.

MOURA, Dante Henrique. Educação básica e educação profissional: dualidade histórica e perspectivas de integração. Anais da 30ª Reunião Anual da ANPEd. Caxambu: ANPEd, 2007.

MOURA, Dante Henrique; BARACHO, Maria Das Graças. Redimensionamento do Projeto Pedagógico do Centro Federal de Educação Tecnológica do Rio Grande do Norte: processo de Construção Coletiva de um Currículo. In: Anais IV Seminário Regional de Política e administração da educação do Nordeste, Natal, 2006.

MOURA, Dante Henrique. A função social da rede federal de educação profissional e tecnológica na educação brasileira. Tecnologia \& Desenvolvimento Sustentável, v. 1, p. 3-23, 2007.

RAMOS, Marise Nogueira. O "novo ensino médio" à luz de antigos princípios: trabalho, ciência e cultura. Boletim Técnico do Senac, vol. 29, n. 2. Rio de Janeiro, pp. 19-27, maio/agosto, 2003.

RAMOS, Marise Nogueira. Integração Curricular dos Ensinos Médio e Técnico: Dimensões Políticas e Pedagógicas. Disponível em: 
$<$ http://www.diaadiaeducacao.pr.gov.br/portals/portal/institucional/dep/fc_integraca o.pdf >. Acesso em: 25.04.2008.

SANTOMÉ, Jurjo Torres. Globalização e interdisciplinaridade: o currículo integrado. Porto Alegre: Editora Artes Médicas Sul Ltda, 1998.

\section{VEIGA, IIma Passos Alencastro (Org.) Projeto Político Pedagógico da Escola:} uma construção possível. São Paulo: Papirus, 2006.

\footnotetext{
${ }^{1}$ Professor do IFRN. Engenheiro Eletricista. Doutor em Educação.

2 Para aprofundamento acerca dessas questões sugerimos consultar: Kuenzer (1997); Ramos (2001); Lima Filho; Garcia (2004); Frigotto; Ciavatta; Ramos (2005); Frigotto; Ciavatta (2006); Moura (2007); Baracho; Silva; Moura; Pereira (2007); e Machado (2006).
}
${ }^{3}$ Não faremos uma discussão exaustiva sobre o tema. Nosso objetivo aqui é esclarecer nossa compreensão acerca de conceitos centrais no desenvolvimento do restante do artigo. Assim, para um maior aprofundamento sugerimos ver: Frigotto; Ciavatta; Ramos (2005); Ramos (2003); e Ramos (?) - - $\quad$ Disponível em http://www.diaadiaeducacao.pr.gov.br/portals/portal/institucional/dep/fc_integracao.pdf. Acesso 25.04.2008-.
${ }^{4}$ É importante esclarecer que compreendemos o trabalho como princípio educativo, considerando, portanto, o seu caráter histórico e ontológico na produção da existência humana. Nesse sentido, compreendemos que uma prática pedagógica significativa demanda análises sobre o mundo do trabalho (sem reduzi-lo apenas ao espaço onde ocorre o trabalho assalariado), incluindo, a sua cultura, os conflitos nele existentes e suas vinculações aos projetos societários em dispuita, suas relações com e implicações sobre a natureza, os conhecimentos construídos a partir do trabalho e das relações sociais que se estabelecem na sua produção etc..

http://www.diaadiaeducacao.pr.gov.br/portals/portal/institucional/dep/fc_integracao.pdf. Acesso 25.04.2008.

${ }^{6}$ RAMOS, Marise Nogueira. O Projeto Unitário de Ensino Médio sob os Princípios do Trabalho, da Ciência e da Cultura. In: FRIGOTTO, Gaudêncio; CIAVATTA, Maria. (Org.). Ensino Médio: Ciência, Cultura e Trabalho. Brasília, 2004.

RAMOS, Marise. Possibilidades e desafios na organização do currículo integrado. In: RAMOS, Marise; FRIGOTTO, Gaudêncio; CIAVATTA, Maria (Orgs.). Ensino Médio Integrado: Concepção e Contradições. São Paulo: Cortez, 2005; pp. 106-127.

7 GRAMSCI, Antonio. Concepção dialética da história. 9.ed. Rio de Janeiro: Civilização Brasileira, 1966.

${ }^{8}$ Essa questão é muito mais complexa, entretanto, como sua discussão não faz parte de nosso objeto de estudo neste trabalho sugerimos ver Moura (2007), onde faço uma análise mais aprofunda acerca dessa e de outras questões relacionadas com a dualidade estrutural histórica entre a educação profissional e a educação básica na sociedade brasileira. 
${ }^{9} \mathrm{O}$ processo que resultou nesse instrumento legal também é bastante complexo e rico, mas não se constitui em objeto de análise deste artigo. Sugerimos consultar: CIAVATTA, M.; FRIGOTTO, G.; RAMOS, M. N. A gênese do Decreto no. 5.154/2004: um debate no contexto controverso da democracia restrita. Trabalho necessário. Revista Eletrônica do neddate. Disponível em <http://www.uff.br/trabalhonecessario/MMGTN3.htm>. Acesso 09.08.2005.

RECEBIDO EM: 03.06.2012

APROVADO EM: 05.07.2012 